\title{
Bazı Çilek (Fragaria $x$ ananassa L.) Çeşitlerinin Tuz Stresine Tepkileri
}

\author{
Özlem ÜZAL ${ }^{1 *}$ Kenan YILDIZ ${ }^{2}$

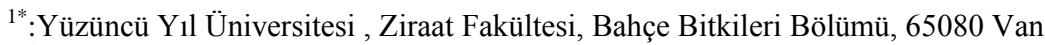 \\ ${ }^{2}$ : Gaziosmanpaşa Üniversitesi, Ziraat Fakültesi, Bahçe Bitkileri Bölümü, Tokat \\ *e-posta: ozlemuzal@yyu.edu.tr
}

Özet: Çalışmada 9 farklı çilek çeşidi (Redland Hope, Sweet Charlie, Carmine, California Giant 4, California Giant 2, California Giant 5, California Giant 3, Kabarla, Camarosa) 'nin $2000 \mathrm{mg} / \mathrm{L} \mathrm{NaCl}$ uygulamasına tepkilerinin belirlenmesi amaçlanmıştır. Yapraklarda tuzdan kaynaklanan semptomlara ve bitki gelişme parametrelerine göre yapılan değerlendirmede, incelenen çeşitler içerisinde Redland Hope, Kabarla çeşitleri daha tolerant, California Giant 5 (CG 5), Carmine çeşitleri ise daha hassas olarak belirlenmiştir. Tuz uygulamasının bütün çeşitlerde yaprak $\mathrm{Na}^{+}$ve $\mathrm{Cl}^{-}$iyonu içeriğini önemli derecede artırdığı görülmüştür. Bunun yanında tuzdan kaynaklanan semptomların daha fazla olduğu tespit edilen çeşitlerin (CG5, Carmine, CG4) yapraklarında daha fazla $\mathrm{Na}^{+}$ve $\mathrm{Cl}^{-}$iyonu biriktirdiği, $\mathrm{K}^{+} / \mathrm{Na}^{+}$oranının da tuza toleransın belirlenmesinde önemli bir ölçüt olarak kullanılabileceği belirlenmiştir. Bitkilerin yapraklarındaki zararlanmanın $\mathrm{K}^{+} / \mathrm{Na}^{+}$oranı yüksek olan çeşitlerde, daha az olduğu tespit edilmiştir.

Anahtar kelimeler: Çilek, Çeşit, $\mathrm{NaCl}$, Oksidatif stres, $\mathrm{K} / \mathrm{Na}$

\section{Responses of Some Strawberry (Fragaria $x$ ananassa L.) Cultivars to Salt Stress}

Abstract: In the study, it was aimed to determine the response of 9 different strawberry cultivars (Redland Hope, Sweet Charlie, Carmine, California Giant 4, California Giant 2, California Giant 5, California Giant 3, Kabarla, Camarosa) to $2000 \mathrm{mgL}^{-1} \mathrm{NaCl}$. In according to symptoms observed on leaves and plant growth parameters, Redland Hope and Kabarla cultivars were found to be more tolerant. On the other hand, Calfornia Giant 5 (CG 5) and Carmine cultivars were more sensitive to NaCl. Salt treatment increased $\mathrm{Na}^{+}$and $\mathrm{Cl}^{-}$ions contents of leaves in all cultivars. The symptoms caused by $\mathrm{NaCl}$ were more on leaves of the cultivars accumulated more $\mathrm{Na}^{+}$and $\mathrm{Cl}^{-}$ions. In addition to accumulation of $\mathrm{Na}^{+}$and $\mathrm{Cl}^{-}$ions, $\mathrm{K}^{+} / \mathrm{Na}^{+}$ratio was appeared to be important criteria for determination of salt tolerant situation in strawberry. The damage caused by salt was less in cultivars having higher $\mathrm{K}^{+} / \mathrm{Na}^{+}$ratios.

Key words: Cultivar, Strawberry, $\mathrm{NaCl}$, Oxidative stress, $\mathrm{K} / \mathrm{Na}$

\section{Giriș}

Toprakların verimliliğini olumsuz yönde etkileyen, geniş alanların tarım dışı kalmasına neden olan tuz stresi, bugün tarımsal üretim alanlarında önemli bir sorundur. Tuzlu toprakların ıslahının ekonomik ve pratik olmaması nedeniyle, son yıllarda tuza dayanıklı bitki tür ve genotiplerin yetiştirilmesi bu alanları değerlendirmede en akılcı yoldur. Son yıllarda da tuza dayanıklı bitki türleri ile bunlara ait tuza toleransı yüksek genotiplerin seçilmesi çok sayıda araştırıcının ilgi odağı olmuş, yoğun araştırmalar yapılmış ve yapilmaya devam etmektedir.

Tuza karşı gösterilen tepki bakımından, bitki türleri ve çeşitleri ve hatta bitki organları arasında önemli farklılıklar bulunmaktadır (Belkhodja et al.1994). Birçok bitkide olduğu gibi, tuza dayanım açısından çilek bitkisinde çeşitler arasında farklılıkların olduğu bilinmektedir (Barroso and Alverez 1997; Turhan 2002; Saied et al. 2005; Kurunc ve Cekic 2005).

Diğer birçok ülkede olduğu gibi yurdumuzda da çeşitli nedenlerle tuzluluk problemi gün geçtikçe artmaktadır. Yanlış sulama ve aşırı gübrelemeyle birlikte drenaj yetersizliğinden dolayı (Epstein ve ark., 1980), tuzluluk problemi giderek daha ciddi boyutlara ulaşmaktadır. Özellikle konunun ciddiyetinin son zamanlarda anlaşılmasına paralel olarak değişik yönlü çalışmalara ağırlık verilmesi ve süratle 
tamamlanması büyük önem taşımaktadır. Sonuçlarını verdiğimiz bu çalışmada farklı çilek çeşitlerinin tuza tolerans durumları ve verdikleri tepkiler belirlenmeye çalışılmıştır.

\section{Materyal ve Metot}

Araştırma Yüzüncü Y1l Üniversitesi Ziraat Fakültesi Bahçe Bitkileri Bölümü Fizyoloji laboratuarında bulunan iklim odasında yürütülmüştür. Çalışmada materyal olarak Redland Hope,Sweet Charlie, Carmine, California Giant 4, California Giant 2, California Giant 5, California Giant 3, Kabarla, Camarosa olmak üzere 9 adet çilek çeşidi kullanılmıştır.

9 çilek çeşidi tuza tolerans bakımından karşılaştırılmıştır. Çeşitlerin tolerans durumlarının belirlemesinde, bazı temel büyüme parametreleri, yapraklardaki semptomlara göre yapılan skala ve fizyolojik değişimler göz önüne alınmıştır. Yapılan bu değerlendirmeler sonucunda dayanıklı ve duyarlı çeşitler tespit edilmiştir.

Çalışma normal atmosferin sağlandığı split klimalı iklim odasında ve su kültüründe yapılmıştır. Temin edilen frigo çilek fidelerinde öncelikle kök budaması yapılmıştır. Su kültürü için 40x25x15 cm boyutlarındaki plastik küvetler kullanılmıştır. Özel olarak hazırlanmış ve her fỉde için delikler açılmış sert strafor tablalara çilek fideleri pamuk ve maşalar yardımıyla yerleştirilmiştir. Bitki kökleri besin çözeltisinde olacak şekilde tablalar küvetlerin üzerine konulmuştur. Havalandırma işlemi ise büyük akvaryum pompası ile yapılmıştır. Deneme tam şansa bağlı deneme desenine göre üç tekerrürlü her tekerrürde 20 bitki olacak şekilde kurulmuştur. Fideler iki hafta süreyle 1/2 Hogland besin çözeltisi (Hoagland and Arnon 1938) ihtiva eden su kültüründe tutulmuştur. Birer haftalık aralarla besin çözeltileri (1/2 Hogland) değiştirilmiştir.

Besin çözeltisinde iki haftalık bir gelişme döneminden sonra tuz uygulamasına başlanmıştır. Tuz uygulanacak fideler için besin çözeltisine ilk gün $1000 \mathrm{mg} / \mathrm{L}$ tuz, ikinci gün ise $1000 \mathrm{mg} / \mathrm{L}$ olacak şekilde final konsantrasyonu olan $2000 \mathrm{mg} / \mathrm{L}$ sağlayacak şekilde kademeli olarak $\mathrm{NaCl}$ ilave edilmiştir. Her hafta yinelenen çözeltilerin tazelenmesi aşamasında, tuz uygulamalarının aynı konsantrasyonda devamı sağlanmıştır.

Örnek alma işlemi tuz uygulamadan hemen önce (0.gün), tuz uygulamasının 10. gün ve 20. günü olmak üzere üç defada yapılmıştır.

Kontrol ve tuz uygulamalarında her bir tekerrür için altı bitki rastlantısal olarak seçilerek, kök, gövde ve yaprakları ayrılarak ayrı ayrı 1/10000 hassasiyetteki dijital terazide tartılmış böylece yaş ağırlıkları (g) belirlenmiştir. Ayrıca bitki başına yaprak sayısı belirlenmiştir. Yaprak alanı el planimetresi kullanılarak $\mathrm{cm}^{2}$ olarak ölçülmüştür.

Tuz uygulamasının 10. ve 20. günü aşağıda belirtilen yapraklarda görülen belirtilere göre bitkilere 1-5 arası puan verilmiştir.

1: Bitkinin tuz stresinden hiç etkilenmemesi

2: Büyümede yavaşlama, yapraklarda lokal sararma ve kıvrılma

3: Yapraklarda sararma ve $\% 25$ oranında nekrotik lekelenmeler

4: Yapraklarda \%50-75 arasında nekrotik leke göstermesi ve dökülmesi, ölümlerin görülmesi

5: Yapraklarda \%75-100 oranında şiddetli nekroz görülmesi veya bitkinin tamamen ölmesi

İyon analizleri için alınan örnekler analiz yapılıncaya kadar $-18{ }^{\circ} \mathrm{C}$ deki derin dondurucuda saklanmıştır. Bitkilerin yaprak dokularındaki iyon analizleri yaş yakma yöntemine göre yapılmıştır. Her bir yaprak

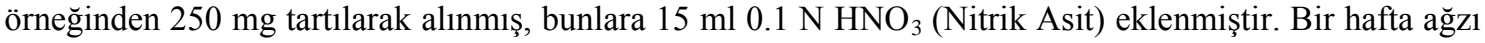
kapalı kap içinde karanlık ve oda sıcaklığında bekletildikten sonra örnekler çalkalayıcıya alınmıştır. Çalkalayıcıda 24 saat çalkalanmıştır. Çalkalama sonunda örnekler süzülerek ekstraktlar elde edilmiştir. $\mathrm{Bu}$ ekstraktlarda $\mathrm{Na}^{+}, \mathrm{K}^{+}, \mathrm{Ca}^{+2}$ iyonları flame fotometrik yöntemle (Jenway Flame Fotometer), $\mathrm{Cl}^{-}$iyonu ise gümüş iyonları ile klorimetrik amperometrik titrasyon yoluyla analiz yapan otomatik bir kloridometre (Sherwood MK II Chloride Analizer 926) ile ölçülmüştür. Yaş yaprak örneğindeki iyon+ miktarı $\mu \mathrm{g} / \mathrm{mg}$ taze ağırlık ( $\mu \mathrm{g} / \mathrm{mg}$ T.A) olarak belirlenmiştir (Taleisnik ve ark. 1997). 
Deneme tam şansa bağlı tesadüf parselleri deneme desenine göre 3 tekerrürlü olarak kurulmuştur. Elde edilen sonuçlar varyans analizine tabi tutulduktan sonra, uygulama ortalamaları Duncan çoklu karşılaştırma testi ile karşılaştırılmıştır.

Ayrıca, yapraklarda zarar durumunu belirten skala değerleri ile iyon içerikleri arasındaki korelasyonlar belirlenmiştir. Analizler SAS Institue (1985) paket programı kullanılarak yapılmıştır.

\section{Bulgular ve Tartışma}

9 çilek çeşidi ile yapılan çalışmada tuza dayanım bakımından çeşitler arasında önemli farklılıklar bulunmuştur. Nitekim bu konuda yapılan diğer çalışmalarda da tuza dayanım açısından çilek bitkisinde çeşitler arasında farklılıkların olduğu bildirilmiştir (Barrosa ve Alverez 1997, Turhan 2002). Yapılan denemelerde kullanılan toksik düzeyde tuz uygulaması ile çilek bitkisinde ilk olarak yaşlı yapraklardan başlayarak sararma ve nekroze olma şeklinde semptomatik etkiler görülmüştür. Bunu takip eden semptomatik etkisi ise, bitkilerin biyokütle ağırlığında (özellikle yaprak ağırlığında) ve yaprak alanlarında azalmalar şeklinde olmuştur. Tuzun etkisi ile yaprak ağırlığında azalma en belirgin olarak, CG 5, CG 3, Carmine çilek çeşitlerinde görülmüştür (Tablo 6,7,3). İlerleyen günlerde yaşlı yaprakların kuruyarak dökülmesi, büyümenin sınırlanması ve sonuçta hassas çeşitlerde bitki ölümü gerçekleşmiştir. Çileklerde tuz fazlalığının, gelişmenin baskı altında kalmasına neden olduğu ve buna bağlı olarak zararlanmaların ve bitkisel özelliklerde ciddi azalmaların görülmesine sebep olduğu, toprakta bulunan tuz konsantrasyonuna bağlı olarak, yaprakların kenarlarından içeriye doğru ilerleyen kurumaların belirgin olarak ortaya çıktığı kaydedilmiştir. (Cassierra-Posada ve Garcia, 2005).

Sivritepe (1995) asmalarda tuzun yapraklarda nekrozlara ve dökümlere neden olduğunu ve artan konsantrasyonlara bağlı olarak tuzun bu zararlandırıcı etkilerinin şiddetlendiğini belirtmiştir. Çilek, turunçgiller, fasülye, armut, patlıcan, karpuz ve süs bitkilerinde yapılan çalışmalarda tuzun yapraklarda çeşitli nekrozlara neden olduğunu göstermiştir (Zekri, 1991; Barroso ve Alvarez, 1997; Yaşar, 2003; Yaşar, 2007; Wahome ve ark., 2001a, 2001b). Yine çilek de tuz stresi ile ilgili olarak yapılan diğer bir çalışmada da tuza dayanıklı olarak tespit edilen Festivalna'ya çilek çeşidinde yaprak alanı, kök gelişimi ve meyve iriliğindeki azalmanın tuza hassas Zarya çeşidine oranla daha az olduğu bildirilmektedir (Dobren'Kova ve Goncharova, 1986). Ayrıca farklı bir çalışmada ortamdaki NaCl konsantrasyonunun artmasıyla sürgün sayısı ve canlılık oranının Pajaro ve Tioga' ya kıyasla yüksek olan Tufts çilek çeşidinin tuza daha dayanıklı olduğu belirlenmiştir (Badawi ve ark. 1992).

Tablo 1. Redland Hope çeşidine ait kök, gövde, yaprak yaş ağırlıkları (g/bitki), yaprak sayısı (adet/bitki) ve yaprak alanları $\left(\mathrm{cm}^{2}\right)$

\begin{tabular}{lllllllllll}
\hline Dönem & \multicolumn{2}{c}{ Yaş kök ă̆ırlığı } & \multicolumn{2}{c}{ Yaş Gövde Ă̆ır. } & \multicolumn{2}{c}{ Yaş Yaprak Ă̆ır. } & \multicolumn{2}{c}{ Yaprak sayısı } & \multicolumn{2}{c}{ Yaprak alanı } \\
\cline { 2 - 11 } & Şahit & Tuz & Şahit & Tuz & Şahit & Tuz & Şahit & Tuz & Şahit & Tuz \\
\cline { 2 - 11 } 0.gün & 4.32 & 4.32 & 2.87 & 2.87 & 0.76 & 0.76 & 2.33 & 2.33 & 29.27 & 29.27 \\
10.gün & 4.84 & $6.19^{\text {od }}$ & 2.18 & $3.05^{\text {öd }}$ & 0.74 & $0.88^{\text {öd }}$ & 2.00 & $2.00^{\text {od }}$ & 30.20 & $34.60^{\text {ö }}$ \\
20.gün & 6.94 & $6.08^{\text {od }}$ & 2.93 & $3.37^{\text {öd }}$ & 1.29 & $0.99^{\text {öd }}$ & 3.33 & $3.33^{\text {öd }}$ & 41.367 & $33.00^{\text {öd }}$ \\
\hline
\end{tabular}

öd: Aynı dönemdeki şahit uygulamasına göre istatistiksel olarak önemsiz

Tablo 2. Sweet Charlie çeşidine ait kök, gövde, yaprak yaş ağırlıkları (g/bitki), yaprak sayısı (adet/bitki) ve yaprak alanları $\left(\mathrm{cm}^{2}\right)$

\begin{tabular}{lllllllllll}
\hline Dönem & \multicolumn{2}{c}{ Yaş kök ă̆ırlığı } & \multicolumn{2}{c}{ Yaş Gövde Ă̆ır. } & \multicolumn{2}{c}{ Yaş Yaprak Ă̆ır. } & \multicolumn{2}{c}{ Yaprak sayısı } & \multicolumn{2}{c}{ Yaprak alanı } \\
\cline { 2 - 12 } & Şahit & Tuz & Şahit & Tuz & Şahit & Tuz & Şahit & Tuz & Şahit & Tuz \\
\cline { 2 - 11 } 0.gün & 4.79 & $4.79^{\text {öd }}$ & 2.59 & $2.59^{\text {öd }}$ & 0.86 & 0.86 & 1.67 & 1.67 & 38.90 & 38.90 \\
10.gün & 6.25 & $4.17^{\text {od }}$ & 3.10 & $1.35^{*}$ & 1.82 & $1.33^{\text {od }}$ & 3.00 & $2.67^{\text {od }}$ & 90.27 & $85.33^{\text {od }}$ \\
20.gün & 6.05 & $5.52^{\text {od }}$ & 2.55 & $1.82^{\text {od }}$ & 1.98 & $2.58^{\text {od }}$ & 3.33 & $3.33^{\text {od }}$ & 86.13 & $122.77^{\text {od }}$ \\
\hline
\end{tabular}

öd: Aynı dönemdeki şahit uygulamasına göre istatistiksel olarak önemsiz

*: Aynı dönemdeki şahit uygulamasına göre istatistiksel olarak önemli $(\mathrm{P}<0.05)$ 
Tablo 3. Carmine çeşidine ait kök, gövde, yaprak yaş ağırlıkları (g/bitki), yaprak sayısı (adet/bitki) ve yaprak alanları $\left(\mathrm{cm}^{2}\right)$

\begin{tabular}{lllllllllll}
\hline Dönem & \multicolumn{2}{c}{ Yaş kök ağırlığı } & \multicolumn{2}{c}{ Yaş Gövde Ă̆ır. } & \multicolumn{2}{c}{ Yaş Yaprak Ă̆ır. } & \multicolumn{2}{c}{ Yaprak sayısı } & \multicolumn{2}{c}{ Yaprak alanı } \\
\cline { 2 - 12 } & Şahit & Tuz & Şahit & Tuz & Şahit & Tuz & Şahit & Tuz & Şahit & Tuz \\
\cline { 2 - 10 } 0.gün & 5.85 & 5.85 & 4.18 & 4.18 & 0.86 & 0.86 & 2.67 & 2.67 & 34.90 & 34.90 \\
10.gün & 10.32 & $5.82^{*}$ & 3.37 & $2.39^{\text {öd }}$ & 1.71 & $1.37^{\text {öd }}$ & 3.00 & $3.00^{\text {öd }}$ & 72.53 & $72.63^{\text {od }}$ \\
20.gün & 7.25 & $9.17^{\text {öd }}$ & 3.33 & $3.18^{\text {öd }}$ & 2.08 & $0.94^{*}$ & 4.33 & $2.67^{*}$ & 81.967 & $36.83^{*}$ \\
\hline
\end{tabular}

öd: Aynı dönemdeki şahit uygulamasına göre istatistiksel olarak önemsiz

*: Aynı dönemdeki şahit uygulamasına göre istatistiksel olarak önemli $(\mathrm{P}<0.05)$

Tablo 4. California Giant 4 (CG 4) çeşidine ait kök, gövde, yaprak yaş ağırlıkları (g/bitki), yaprak sayısı (adet/bitki) ve yaprak alanları $\left(\mathrm{cm}^{2}\right)$

\begin{tabular}{lllllllllll}
\hline \multirow{2}{*}{ Dönem } & \multicolumn{2}{c}{ Yaş kök ağırlığı } & \multicolumn{2}{c}{ Yaş Gövde Ă̆ır. } & \multicolumn{2}{c}{ Yaş Yaprak Ă̆ır. } & \multicolumn{2}{c}{ Yaprak sayısı } & \multicolumn{2}{c}{ Yaprak alanı } \\
\cline { 2 - 11 } & Şahit & Tuz & Şahit & Tuz & Şahit & Tuz & Şahit & Tuz & Şahit & Tuz \\
\cline { 2 - 10 } 0.gün & 5.63 & 5.63 & 4.44 & 4.44 & 0.94 & 0.94 & 4.00 & 4.00 & 39.33 & 39.33 \\
10.gün & 5.94 & $7.68^{\text {öd }}$ & 2.92 & $3.36^{\text {öd }}$ & 1.41 & $1.23^{\text {ö }}$ & 4.00 & $3.33^{\text {öd }}$ & 77.57 & $57.27^{\text {öd }}$ \\
20.gün & 7.36 & $8.49^{\text {öd }}$ & 4.68 & $4.66^{\text {öd }}$ & 2.63 & $1.56^{*}$ & 4.67 & $3.33^{\text {od }}$ & 108.53 & $68.13^{*}$ \\
\hline
\end{tabular}

öd: Aynı dönemdeki şahit uygulamasına göre istatistiksel olarak önemsiz

*: Aynı dönemdeki şahit uygulamasına göre istatistiksel olarak önemli $(\mathrm{P}<0.05)$

Tablo 5. California Giant 2 (CG 2) çeşidine ait kök, gövde, yaprak yaş ağırlıkları (g/bitki), yaprak sayısı (adet/bitki) ve yaprak alanları $\left(\mathrm{cm}^{2}\right)$

\begin{tabular}{lllllllllll}
\hline \multirow{2}{*}{ Dönem } & \multicolumn{2}{c}{ Yaş kök ă̆ırlığı } & \multicolumn{2}{c}{ Yaş Gövde Ă̆ır. } & \multicolumn{2}{c}{ Yaş Yaprak Ă̆ır. } & \multicolumn{2}{c}{ Yaprak sayısı } & \multicolumn{2}{c}{ Yaprak alanı } \\
\cline { 2 - 11 } & Şahit & Tuz & Şahit & Tuz & Şahit & Tuz & Şahit & Tuz & Şahit & Tuz \\
\cline { 2 - 10 } 0.gün & 4.28 & 4.28 & 3.10 & 3.10 & 0.89 & 0.89 & 2.33 & 2.33 & 37.73 & 37.73 \\
10.gün & 6.51 & $8.05^{\text {öd }}$ & 3.43 & $3.50^{\text {öd }}$ & 1.79 & $1.04^{*}$ & 3.33 & $2.67^{\text {öd }}$ & 85.40 & $56.93^{\text {od }}$ \\
20.gün & 7.19 & $6.95^{\text {öd }}$ & 5.37 & $2.53^{*}$ & 2.97 & $1.74^{*}$ & 5.00 & $3.67^{\text {öd }}$ & 108.27 & $75.60^{*}$ \\
\hline
\end{tabular}

öd: Aynı dönemdeki şahit uygulamasına göre istatistiksel olarak önemsiz

*: Aynı dönemdeki şahit uygulamasına göre istatistiksel olarak önemli $(\mathrm{P}<0.05)$

Tablo 6. California Giant 5 (CG 5) çeşidine ait kök, gövde, yaprak yaş ağırlıkları (g/bitki), yaprak sayısı (adet/bitki) ve yaprak alanları $\left(\mathrm{cm}^{2}\right)$

\begin{tabular}{lllllllllll}
\hline \multirow{2}{*}{ Dönem } & \multicolumn{2}{c}{ Yaş kök ağırlığı } & \multicolumn{2}{c}{ Yaş Gövde Ağır. } & \multicolumn{2}{c}{ Yaş Yaprak Ă̆ır. } & \multicolumn{2}{c}{ Yaprak sayısı } & \multicolumn{2}{c}{ Yaprak alanı } \\
\cline { 2 - 12 } & Şahit & Tuz & Şahit & Tuz & Şahit & Tuz & Şahit & Tuz & Şahit & Tuz \\
\cline { 2 - 11 } 0.gün & 3.80 & 3.80 & 2.46 & 2.46 & 1.01 & 1.01 & 3.33 & 3.33 & 46.77 & 46.77 \\
10.gün & 5.26 & $5.57^{\text {öd }}$ & 2.70 & $3.04^{\text {öd }}$ & 1.25 & $1.39^{\text {öd }}$ & 3.67 & $3.33^{\text {ö }}$ & 60.23 & $81.97^{\text {od }}$ \\
20.gün & 5.19 & $6.65^{\text {od }}$ & 4.25 & $2.23^{*}$ & 2.31 & $0.57^{*}$ & 3.67 & $3.00^{\text {od }}$ & 95.97 & $31.50^{*}$ \\
\hline
\end{tabular}

öd: Aynı dönemdeki şahit uygulamasına göre istatistiksel olarak önemsiz

*: Aynı dönemdeki şahit uygulamasına göre istatistiksel olarak önemli $(\mathrm{P}<0.05)$

Tablo 7. California Giant 3 (CG 3) çeşidine ait kök, gövde, yaprak yaş ağırlıkları (g/bitki), yaprak sayısı (adet/bitki) ve yaprak alanları $\left(\mathrm{cm}^{2}\right)$

\begin{tabular}{lllllllllll}
\hline \multirow{2}{*}{ Dönem } & \multicolumn{2}{c}{ Yaş kök ağırlığı } & \multicolumn{2}{c}{ Yaş Gövde Ă̆ır. } & \multicolumn{2}{c}{ Yaş Yaprak Ă̆ır. } & Yaprak sayısı & \multicolumn{2}{c}{ Yaprak alanı } \\
\cline { 2 - 11 } & Şahit & Tuz & Şahit & Tuz & Şahit & Tuz & Şahit & Tuz & Şahit & Tuz \\
\cline { 2 - 11 } 0.gün & 4.93 & 4.93 & 2.69 & 2.69 & 1.12 & 1.12 & 3.67 & 3.67 & 58.97 & 58.97 \\
10.gün & 6.63 & $6.47^{\text {öd }}$ & 3.36 & $2.88^{\text {öd }}$ & 2.71 & $1.26^{*}$ & 4.33 & $3.00^{\text {ö }}$ & 105.40 & $70.27^{*}$ \\
20.gün & 5.74 & $5.82^{\text {od }}$ & 2.70 & $3.28^{\text {od }}$ & 2.71 & $1.49^{*}$ & 5.33 & $4.00^{\text {öd }}$ & 132.87 & $66.77^{*}$ \\
\hline
\end{tabular}

öd: Aynı dönemdeki şahit uygulamasına göre istatistiksel olarak önemsiz

*: Aynı dönemdeki şahit uygulamasına göre istatistiksel olarak önemli $(\mathrm{P}<0.05)$ 
Tablo 8. Kabarla çeşidine ait kök, gövde, yaprak yaş ağırlıkları (g/bitki), yaprak sayısı (adet/bitki) ve yaprak alanları $\left(\mathrm{cm}^{2}\right)$

\begin{tabular}{|c|c|c|c|c|c|c|c|c|c|c|}
\hline \multirow[t]{2}{*}{ Dönem } & \multicolumn{2}{|c|}{ Yaş kök ağırlığı } & \multicolumn{2}{|c|}{ Yaş Gövde Ă̆ır. } & \multicolumn{2}{|c|}{ Yaş Yaprak Ağır. } & \multicolumn{2}{|c|}{ Yaprak sayısı } & \multicolumn{2}{|c|}{ Yaprak alanı } \\
\hline & Şahit & Tuz & Şahit & Tuz & Şahit & Tuz & Şahit & Tuz & Şahit & Tuz \\
\hline 0.gün & 2.93 & 2.93 & 1.67 & 1.67 & 0.87 & 0.87 & 2.33 & 2.33 & 42.97 & 42.97 \\
\hline 10.gün & 2.76 & $3.20^{\text {öd }}$ & 0.82 & $1.27^{\text {öd }}$ & 1.38 & $0.85^{\text {öd }}$ & 3.00 & 2.33 & 72.07 & $37.10^{*}$ \\
\hline 20.gün & 5.34 & $5.63^{\text {öd }}$ & 1.38 & $1.85^{\text {öd }}$ & 3.05 & $2.11^{*}$ & 4.33 & $4.00^{\text {öd }}$ & 142.60 & $101.47^{*}$ \\
\hline
\end{tabular}

öd: Aynı dönemdeki şahit uygulamasına göre istatistiksel olarak önemsiz

*: Aynı dönemdeki şahit uygulamasına göre istatistiksel olarak önemli $(\mathrm{P}<0.05)$

Tablo 9. Camarosa çeşidine ait kök, gövde, yaprak yaş ağırlıkları (g/bitki), yaprak sayısı (adet/bitki) ve yaprak alanları $\left(\mathrm{cm}^{2}\right)$

\begin{tabular}{lllllllllll}
\hline Dönem & \multicolumn{2}{c}{ Yaş kök ă̆ırlığı } & \multicolumn{2}{c}{ Yaş Gövde Ă̆ır. } & \multicolumn{2}{c}{ Yaş Yaprak Ă̆ır. } & \multicolumn{2}{c}{ Yaprak sayısı } & \multicolumn{2}{c}{ Yaprak alanı } \\
\cline { 2 - 10 } & Şahit & Tuz & Şahit & Tuz & Şahit & Tuz & Şahit & Tuz & Şahit & Tuz \\
\cline { 2 - 10 } 0.gün & 2.04 & 2.04 & 0.68 & 0.68 & 0.78 & 0.78 & 2.00 & 2.00 & 46.70 & 46.70 \\
10.gün & 2.27 & $2.06^{\text {öd }}$ & 0.77 & $0.83^{\text {öd }}$ & 1.27 & $0.99^{\text {öd }}$ & 3.00 & $2.33^{\text {öd }}$ & 65.13 & $64.20^{\text {od }}$ \\
20.gün & 2.66 & $3.74^{*}$ & 0.99 & $1.03^{\text {öd }}$ & 1.59 & $1.56^{\text {od }}$ & 3.67 & $3.33^{\text {od }}$ & 86.00 & $80.77^{\text {od }}$ \\
\hline
\end{tabular}

öd: Aynı dönemdeki şahit uygulamasına göre istatistiksel olarak önemsiz

*: Aynı dönemdeki şahit uygulamasına göre istatistiksel olarak önemli $(\mathrm{P}<0.05)$

Bitki gelişimi ile ilgili parametreler olarak bakıldığında yeşil aksamın çilekte tuz stresinden ilk ve en fazla etkilenen kısmı olduğu görülmüştür (Tablo 1, 2, 3, 4, 5, 6, 7, 8, 9). Yaprak ağırlığı ve yaprak alanı tuz stresi koşullarında belirgin şekilde azalmış ve bu azalma uygulama sürelerine bağlı olarak bazı çeşitlerde (CG 5, CG 3, CG 2, Carmine) çok fazla olurken (Tablo 6, 7, 5, 3), tuza tolerant bazı çeşitlerde (Redland Hope, Sweet Charlie, Camarosa) çok az olmuştur (Tablo 1, 2, 9). Bitkilerde morfolojik olarak ortaya çıkan zararlanmanın derecesini ortaya koymak amacıyla yapılan skala oluşturma yönteminde belirtildiği şekilde bitkilere 1 ile 5'e kadar puan verilmiştir. Buna göre her iki dönem içinde en düşük puan alan çilek çeşidinin Redland Hope olduğu görülmektedir (Tablo 10). Bu değere göre tuzdan en az etkilenen çeşit Redland Hope çeşididir. Bunu Kabarla ve Sweet Charlie çeşitleri izlemektedir. 10. gün ve 20. gün itibariyle tuza dayanım skalasından en yüksek puanı alıp, morfolojik olarak en fazla zararlanan çeşit CG 5 çeşidi olduğu belirlenmiştir. Bu çeşidi sırasıyla Carmine ve CG 4 izlemektedir (Tablo 10).

Çalışma sonucunda, tuzun zarar düzeyini belirlemek için yapraklardaki semptomlara göre yapılan skala oluşturma yöntemi, kısıtlı koşullarda yapılan çalışmalarda en kolay ve neredeyse biyokimyasal analizler kadar etkin olabileceği görülmüştür. Nitekim Aktaş (2002) ve Yaşar (2003)'ın çalışmalarında biber ve patlıcan türleri için geliştirmiş oldukları skalalardan yararlanmıştır. Aktaş (2002), biberde tuza toleransın belirlenmesinde incelenen özellikler oranında kararlı tutum sergileyen screening için kullanılabilecek bir özellik belirlenmesinin zor olduğunu, en etkin seçim kriterlerinin skala değerleri ile bitkideki $\mathrm{K} / \mathrm{Na}$ iyonlarının oranı olduğunu belirtmiştir.

Tablo 10. Yapraklardaki belirtilere göre tuza dayanım skalası (puan)

\begin{tabular}{lll}
\hline Çeşit & 10.Gün & 20.Gün \\
\hline Redland Hope & 1.00 & 1.00 \\
Sweet Charlie & 2.00 & 3.00 \\
Carmine & 4.00 & 5.00 \\
C.G.4 & 4.00 & 4.00 \\
C.G.2 & 4.00 & 3.75 \\
C.G.5 & 4.75 & 5.00 \\
C.G.3 & 3.50 & 3.50 \\
Kabarla & 2.00 & 2.00 \\
Camarosa & 3.00 & 3.00 \\
\hline
\end{tabular}

Farklı bitki türlerinin kullanıldığı bazı araştırmalarda (Karanlık 2001; Aktaş 2002; Yaşar 2003) ve çilekte yapılan çalışmada (Turhan 2002) tuzdan etkilenmenin $\mathrm{Na}^{+}$ve $\mathrm{Cl}^{-}$iyonlarının birikimi ilgili olduğu ifade 


\section{Ö. ÜZAL, K. YILDIZ}

edilmiştir. Awang ve Athernon (1994) ise; çilekte $\mathrm{NaCl}$ uygulamalarının yalnızca $\mathrm{Cl}^{-}$alımını artırdığını, $\mathrm{Na}^{+}$alımını ise etkilemediğini ve bu bitkinin yüksek tuz konsantrasyonlarına $\mathrm{Na}^{+}$' $u$ yapraklarından uzak tutarak tolerans sağladığını belirtmişlerdir.

Çalışmada, yapraklarında daha fazla $\mathrm{Na}^{+}$ve $\mathrm{Cl}^{-}$iyonu biriktiren çeşitlerde (CG5, Carmine, CG4) zararlanmanın daha fazla olduğu saptanmıştır (Tablo 11). Tuz stresi altında, bitki gelişimi bakımından, çilek çeşitleri arasında farklılıkların olmasının en önemli sebebi, çeşitlerin bünyelerinde $\mathrm{Na}^{+}$ve $\mathrm{Cl}^{-}$ iyonlarını farklı düzeylerde biriktirmelerine bağlanabilir. Nitekim Saied ve ark. (2003) Elsanta ve Korana çeşitlerine 80 ve $60 \mathrm{mM} \mathrm{NaCl}$ uygulaması ile yaprak yüzeyinde gözlemlerle ilgili yapılan bir çalışmada Korana çeşidinin daha az lekelendiği gözlemlemişlerdir. Korana çeşidinin köklerindeki $\mathrm{Cl}^{-}$miktarı, Elsanto çeşitine göre önemli düzeyde artmıştır. Karona çeşidinin $\mathrm{Cl}^{-}$iyonlarını köklerde biriktirerek, bitkinin tamamına olumsuz etkide bulunması önlendiğini belirlemişlerdir.

Levitt (1980), ortamda NaCl'nin fazla olması durumunda, bitkiler tarafindan $\mathrm{Na}^{+}$iyonunun gereğinden fazla alındığı ve rekabet nedeniyle $\mathrm{K}^{+}$iyonunda azalma meydana geldiğini bildirmiştir. Aynı şekilde Yaşar ve ark. (2006a) karpuzda yaptıkları tuz uygulamalarının $\mathrm{K}^{+}$miktarını azalttığı belirtmiştir. Turhan (2002), farklı çilek çeşitlerinde 3 farklı tuz konsantrasyonu (500, 1000, 2000 ppm) uyguladığı çalışmada ise uzun ve kısa süreli tuz uygulamalarının toprak üstü organlarda $\mathrm{K}^{+}$miktarını azaltmış olduğunu, toprak altı organlarda ise $\mathrm{K}^{+}$miktarının özellikle uygulama sürelerine ve çeşitlere bağlı olarak önemli değişiklikler gösterdiğini gözlemlemiştir. Ayrıca bitkinin yeşil aksamına $\mathrm{Na}^{+}$gidişini engelleyebilen ve seçici olarak yüksek oranlarda $\mathrm{K}^{+}$gönderen genotiplerin tuz toksisitesine daha dayanıklı olduğu Greenway ve Munns (1980), WynJones ve ark. (1967), Yaşar (2003), Yaşar ve ark. (2006b) tarafindan da bildirilmektedir. Çalışmamızda 10. gün itibariyle bütün çeşitlerin $\mathrm{K}^{+}$iyonu miktarında azda olsa artışlar meydana gelmiş, fakat 20.günde $\mathrm{K}^{+}$iyonunda bazı çeşitlerde azalmalar meydana gelirken, bazılarında artışlar meydana gelmiştir (Tablo 11).

Yapılan çalışmada gerek kalsiyum birikimi gerekse $\mathrm{Ca}^{+2} / \mathrm{Na}^{+}$oranı ile tuzdan kaynaklanan zararlanma arasında anlamlı bir ilişki bulunamamıştır (Tablo 12). Nitekim Yıldız ve ark. (2008)' nın çilekte yaptıkları bir çalışmada, tuza dayanıklı ve hassas çeşitler arasında $\mathrm{Ca}^{+2} / \mathrm{Na}^{+}$oranı açısından önemli bir farkın bulunamadığı kaydedilmiştir. Bu araştırıcılar çilek bitkisi için bu parametrenin tuza dayanımı belirlemede uygun bir kıstas olmadığını belirtmişlerdir. Yine Yaşar ve ark.(2007)'nın tuz stresi altındaki karpuzların genotipik farklılıklarının belirlenmesi başlıklı çalışmalarında gerek $\mathrm{Ca}^{+2}$ birikimi gerekse $\mathrm{Ca}^{+2} / \mathrm{Na}^{+}$ oranının, inceledikleri diğer parametrelerle herhangi bir uyum içinde olmadığını belirtmişlerdir.

Yapraklarında $\mathrm{K}^{+} / \mathrm{Na}^{+}$oranı fazla olan çeşitlerde (Camarosa, Redland hope, Kabarla) zararlanmanın daha az olduğu görülmüştür (Tablo 12). Bu sonuç, benzer konuda çalışan birçok araştırıcının bulguları ile uyumludur (Al-Karaki 2002; Yaşar 2003; Yaşar 2007; Yıldız ve ark. 2008). Birçok bitki için literatürde belirtildiği gibi, bu çalışmada da $\mathrm{K}^{+} / \mathrm{Na}^{+}$oranının çilekte tuza toleransın belirlenmesinde etkin bir ölçü olarak kullanılabileceği görülmüştür. 
Tablo 11. $\mathrm{NaCl}$ uygulaması öncesi ve uygulamadan sonraki belirli dönemlerde çeşitlerin yapraklarındaki $\mathrm{Na}^{+}, \mathrm{Cl}^{-}, \mathrm{K}^{+} \mathrm{ve} \mathrm{Ca}^{+2}$ miktarları

\begin{tabular}{|c|c|c|c|c|c|c|c|c|c|c|c|c|}
\hline \multirow[b]{2}{*}{ Çeşit } & \multicolumn{3}{|c|}{$\mathrm{Na}^{+}(\mu \mathrm{g} / \mathrm{mg}$ T.A. $)$} & \multicolumn{3}{|c|}{$\mathrm{Cl}^{-}(\mu \mathrm{g} / \mathrm{mg}$ T.A. $)$} & \multicolumn{3}{|c|}{$\mathrm{K}^{+}(\mu \mathrm{g} / \mathrm{mg}$ YA $)$} & \multicolumn{2}{|c|}{$\mathrm{Ca}^{+2}(\mu \mathrm{g} / \mathrm{mg}$ T.A. $)$} & \multirow[b]{2}{*}{ 20.gün } \\
\hline & 0.gün & 10. gün & 20.gün & 0 . gün & 10.gün & 20.gün & 0 . gün & 10.gün & 20.gün & 0.gün & 10. gün & \\
\hline R. Hope & $6.305 \mathrm{C}^{*} \mathrm{a}^{* *}$ & 11.471 Babc & $18.575 \mathrm{Ac}$ & $0.195 \mathrm{Ba}$ & $1.125 \mathrm{Abc}$ & 1.545 Acd & $1.284 \mathrm{~B}^{*} \mathrm{bc} \mathrm{c}^{* *}$ & 2.120 Aabcd & $2.385 \mathrm{Aab}$ & $0.967 \mathrm{Bcd}$ & $1.693 \mathrm{Aab}$ & $1.167 \mathrm{ABab}$ \\
\hline S.Charlie & $7.384 \mathrm{Ba}$ & $11.840 \mathrm{Babc}$ & $20.156 \mathrm{Abc}$ & $0.339 \mathrm{Ba}$ & $1.224 \mathrm{Abc}$ & $1.594 \mathrm{Acd}$ & $1.077 \mathrm{Bc}$ & 1.932 Aabcd & $2.313 \mathrm{Aab}$ & $1.470 \mathrm{~A} \mathrm{abc}$ & 1.144 Abcd & $1.095 \mathrm{Aab}$ \\
\hline Carmine & $6.288 \mathrm{Ca}$ & $16.481 \mathrm{Ba}$ & $25.854 \mathrm{Aa}$ & $0.247 \mathrm{Ca}$ & $1.348 \mathrm{Bbc}$ & $3.431 \mathrm{Aa}$ & $1.840 \mathrm{Ba}$ & $1.862 \mathrm{Bbcd}$ & $2.696 \mathrm{Aa}$ & $0.755 \mathrm{Ad}$ & 1.348 Abc & 1.099 Aab \\
\hline CG 4 & $6.403 \mathrm{Ba}$ & $9.960 \mathrm{Bbc}$ & $26.255 \mathrm{Aa}$ & $0.312 \mathrm{Ba}$ & $2.239 \mathrm{Aa}$ & $2.454 \mathrm{Ab}$ & $1.360 \mathrm{Cbc}$ & $1.779 \mathrm{Bcd}$ & $2.539 \mathrm{Aab}$ & $0.929 \mathrm{Bcd}$ & $1.981 \mathrm{Aa}$ & $1.335 \mathrm{Ba}$ \\
\hline$C G 2$ & $7.943 \mathrm{Ca}$ & $14.827 \mathrm{Bab}$ & $24.662 \mathrm{Aab}$ & $0.232 \mathrm{Ba}$ & $1.641 \mathrm{Aab}$ & $1.746 \mathrm{Abcd}$ & $1.886 \mathrm{ABa}$ & $2.285 \mathrm{Aab}$ & $1.621 \mathrm{Bc}$ & $1.730 \mathrm{ABab}$ & $2.165 \mathrm{Aa}$ & $1.520 \mathrm{Ba}$ \\
\hline CG 5 & $6.449 \mathrm{Ca}$ & 12.279 Babc & $27.411 \mathrm{Aa}$ & $0.279 \mathrm{Ca}$ & $1.199 \mathrm{Bbc}$ & $2.112 \mathrm{Abc}$ & $1.642 \mathrm{Bab}$ & $1.859 \mathrm{ABbcd}$ & $2.155 \mathrm{Ab}$ & 1.316 Aabcd & $1.331 \mathrm{Abc}$ & $0.654 \mathrm{Ab}$ \\
\hline$C G 3$ & $7.726 \mathrm{Ba}$ & $15.437 \mathrm{Ba}$ & 19.177 Ac & $0.232 \mathrm{Ba}$ & $1.181 \mathrm{Abc}$ & $1.314 \mathrm{Acd}$ & $1.710 \mathrm{Aab}$ & $1.715 \mathrm{Ad}$ & $1.082 \mathrm{Bd}$ & $1.142 \mathrm{Abcd}$ & $1.005 \mathrm{Acd}$ & $1.476 \mathrm{Aa}$ \\
\hline Kabarla & $6.942 \mathrm{Ba}$ & $9.315 \mathrm{Bc}$ & $18.082 \mathrm{Ac}$ & $0.173 \mathrm{Ba}$ & $0.752 \mathrm{ABc}$ & $1.228 \mathrm{Ad}$ & $1.805 \mathrm{Ba}$ & $2.364 \mathrm{Aa}$ & $2.192 \mathrm{ABb}$ & $1.492 \mathrm{Aabc}$ & $0.680 \mathrm{Bd}$ & $1.201 \mathrm{ABab}$ \\
\hline Camarosa & $5.279 \mathrm{Ba}$ & $7.196 \mathrm{Bc}$ & $15.922 \mathrm{Ac}$ & $0.275 \mathrm{Ba}$ & $1.036 \mathrm{Abc}$ & $1.493 \mathrm{Acd}$ & $1.645 \mathrm{Bab}$ & 2.231 Aabc & $2.159 \mathrm{Ab}$ & $1.934 \mathrm{Aa}$ & $1.995 \mathrm{Aa}$ & $1.068 \mathrm{Bab}$ \\
\hline
\end{tabular}

*Aynı büyük harfle gösterilen dönem ortalamaları arasındaki fark istatistiksel olarak önemli değildir.

**Aynı küçük harfle gösterilen çeşit ortalamaları arasındaki fark istatistiksel olarak önemli değildir. 
Tablo 12. NaCl uygulaması öncesi ve uygulamadan sonraki belirli dönemlerde çeşitlerin yapraklarındaki $\mathrm{K} / \mathrm{Na}$ ve $\mathrm{Ca} / \mathrm{Na}$ miktarları

\begin{tabular}{lllllll}
\hline \multicolumn{3}{c}{ K/Na } & \multicolumn{2}{c}{ Ca/Na } \\
\hline Çeşit & 0.gün & 10. gün & 20.gün & 0.gün & 10. gün & 20.gün \\
\hline R. Hope & $0.209 \mathrm{~A}^{*} \mathrm{c}^{* *}$ & $0.190 \mathrm{~A} \mathrm{~b}$ & $0.131 \mathrm{~B} \mathrm{ab}$ & $0.154 \mathrm{~A} \mathrm{bcd}$ & $0.148 \mathrm{~A} \mathrm{~b}$ & $0.064 \mathrm{~B} \mathrm{a}$ \\
S.Charlie & $0.147 \mathrm{~A} \mathrm{~d}$ & $0.166 \mathrm{~A} \mathrm{bc}$ & $0.117 \mathrm{~A} \mathrm{abc}$ & $0.200 \mathrm{~A} \mathrm{bc}$ & $0.101 \mathrm{~B} \mathrm{bc}$ & $0.055 \mathrm{~B} \mathrm{a}$ \\
Carmine & $0.293 \mathrm{~A} \mathrm{ab}$ & $0.116 \mathrm{~B} \mathrm{c}$ & $0.106 \mathrm{~B} \mathrm{abc}$ & $0.123 \mathrm{~A} \mathrm{~d}$ & $0.083 \mathrm{AB} \mathrm{bc}$ & $0.043 \mathrm{~B} \mathrm{a}$ \\
CG 4 & $0.213 \mathrm{~A} \mathrm{c}$ & $0.200 \mathrm{~A} \mathrm{~b}$ & $0.103 \mathrm{~B} \mathrm{abc}$ & $0.144 \mathrm{~B} \mathrm{~cd}$ & $0.219 \mathrm{~A} \mathrm{a}$ & $0.054 \mathrm{C} \mathrm{a}$ \\
CG 2 & $0.237 \mathrm{~A} \mathrm{bc}$ & $0.154 \mathrm{~B} \mathrm{bc}$ & $0.068 \mathrm{C} \mathrm{bc}$ & $0.218 \mathrm{~A} \mathrm{~b}$ & $0.143 \mathrm{~B} \mathrm{~b}$ & $0.062 \mathrm{C} \mathrm{a}$ \\
CG 5 & $0.257 \mathrm{~A} \mathrm{abc}$ & $0.153 \mathrm{~B} \mathrm{bc}$ & $0.079 \mathrm{C} \mathrm{abc}$ & $0.206 \mathrm{~A} \mathrm{bc}$ & $0.109 \mathrm{~B} \mathrm{bc}$ & $0.054 \mathrm{~B} \mathrm{a}$ \\
CG 3 & $0.223 \mathrm{~A} \mathrm{c}$ & $0.113 \mathrm{~B} \mathrm{c}$ & $0.057 \mathrm{~B} \mathrm{c}$ & $0.150 \mathrm{~A} \mathrm{bcd}$ & $0.068 \mathrm{~B} \mathrm{c}$ & $0.034 \mathrm{~B} \mathrm{a}$ \\
Kabarla & $0.263 \mathrm{~A} \mathrm{abc}$ & $0.263 \mathrm{~A} \mathrm{a}$ & $0.122 \mathrm{~B} \mathrm{abc}$ & $0.220 \mathrm{~A} \mathrm{~b}$ & $0.077 \mathrm{~B} \mathrm{bc}$ & $0.067 \mathrm{~B} \mathrm{a}$ \\
Camarosa & $0.316 \mathrm{~A} \mathrm{a}$ & $0.308 \mathrm{~A} \mathrm{a}$ & $0.135 \mathrm{~B} \mathrm{a}$ & $0.368 \mathrm{~A} \mathrm{a}$ & $0.277 \mathrm{~B} \mathrm{a}$ & $0.068 \mathrm{C} \mathrm{a}$ \\
\hline
\end{tabular}

* Aynı büyük harfle gösterilen dönem ortalamaları arasındaki fark istatistiksel olarak önemli değildir.

** Aynı küçük harfle gösterilen çeşit ortalamaları arasındaki fark istatistiksel olarak önemli değildir.

Yine Yaşar ve ark. (2007)'nın tuz stresi altındaki karpuzların genotipik farklılıklarının belirlenmesi başlıklı çalışmalarında gerek $\mathrm{Ca}^{+2}$ birikimi gerekse $\mathrm{Ca}^{+2} / \mathrm{Na}^{+}$oranının, inceledikleri diğer parametrelerle herhangi bir uyum içinde olmadığını belirtmişlerdir. Yaptığımız çalışmada da gerek kalsiyum birikimi gerekse $\mathrm{Ca}^{+2} / \mathrm{Na}^{+}$oranı ile tuzdan kaynaklanan zararlanma arasında anlamlı bir ilişki bulunamamıştır (Tablo 12).

Sonuç olarak yapraklarında daha fazla $\mathrm{Na}$ ve $\mathrm{Cl}$ iyonu biriktiren çeşitlerde (CG5, Carmine, CG4) zararlanmanın daha fazla olduğu, bu çeşitlerinde yapraklarında belirlenen $\mathrm{K}^{+} / \mathrm{Na}^{+}$oranının düşük olduğu dikkati çekmiştir. Yine yapraklarında $\mathrm{K}^{+} / \mathrm{Na}^{+}$oranı fazla olan çeşitlerde (Camarosa, Redland hope, Kabarla, Sweet Charlie) zararlanmanın daha az olduğu görülmüş, bu çeşitlerin yapraklarında daha fazla $\mathrm{Na}^{+}$ve $\mathrm{Cl}^{-}$iyonu biriktirdiği saptanmıştır.

\section{Teşekkür}

Çalışmayı doktora tez projesi (2006-FBE-078) olarak destekleyen Yüzüncü Yıl Üniversitesi Bilimsel Araştırma Projeleri Başkanlığına en içten teşekkürlerimizi arz ederiz.

\section{Kaynaklar}

Aktaş H (2002). Biberde Tuza Dayanıklılığın Fizyolojik Karakterizasyonu ve Kalıtımı. Ç.Ü. Fen Bilimleri Enst. (Doktora tezi, basılmamış), Adana, $105 \mathrm{~s}$.

Al-Karaki GN (2000). Growth, water use efficiency and sodium and potassium acquisition by tomato cultivars grown under Salt stress. J. of Plant Nutrition, 23 (1): 1-8.

Awang YB, Atherton JG (1994). Salinity and shading effects on leaf water relations and ionic composition of strawberry plants grown on rockwool. J. Hort. Sci., 69(2): 377-383.

Badawi MA, Alphonse AZ, Bondok Hosni Y (1992). Effect of some disinfectant treatments and different sodium chloride concentrations on the in vitro growth of some strawberry cultivars. Hort. Abst. $62(5): 3762$.

Barrosa MC, Alvarez CE (1997). Toxicity symptoms and tolerance of strawberry to salinity in the irrigation water. Scientia Horticulturae, 71: 177-188.

Belkhodja R, Morales F, Abadia A, Gomez-Aparisi J, Abadia J (1994). Cholorophyll fluorescence as a possible tool for salinity tolerance screening in barley (Hordeum vulgare L.). Plant Physiol, 104, 667-673.

Casierra-Posada F, Garcia N (2005). Groth ve dry matter partitioning of salt-stressed strawberry cultivars (Fragaria sp.). Agronomia Colombiana, 23 (1): 83-90.

Dobren'Kova LG, Goncharova EA (1986). Growth activity and content of endogenous growth regulators in various organs of strawberry under extreme conditions. Hort. Abst.56 (7): 5100.

Epstein E, Nortlyn JD, Rush DW, Kingbury RW, Keller DB, Cunningeham GA, Wrona AF (1980). Saline culture of crops: A Genetic Approach. Sci.,210:399-404.

Greenway H, Munns R (1980). Mechanisms of Salt Tolerance in Nonhallophytes. Ann. Rev. Plant Physiol., 31: 149-190. 
Hoagland DR, Arnon DI (1938). The water culture method for growing plants without soil. Circ. Calif. Agr. Exp. Sta., 347-461.

Karanlık S (2001). Değişik Buğday Genotiplerinde Tuz Stresine Dayanıklılık ve Dayanıklılığın Fizyolojik Nedenlerinin Araştırılması (Doktora tezi, basılmamış). Ç.Ü. Fen Bil. Enst., Adana.

Kurunc A, Cekic C (2005). Response of three strawberry cultivar (Fragaria $x$ ananassa Duch.) to different salinity levels in irrigation water. Hort. Sci. 32 (2), 50-55.

Levitt J (1980). Responses Of Plants To Environmental Stresses. 2nd ed. Academic Pres, New York, 2: 607.

Saied AS, Keutgen N, Noga G (2003). Effects of NaCl stress on leaf growth, Photosynthesis and ionic contents of strawberry cvs. 'Elsanta' and 'Korona'. Acta Horticulturae, 609: 67-73.

Saied AS, Keutgen N, Noga G (2005). The influence of NaCl salinity on growth, yield and fruit qualty of strawberry cvs. 'Elsanta' and 'Korona'. Sci.Horti., 103, 289-303.

SAS-INSTITUE (1985). SAS/ State User’s Guide 6.03 ed. SAS. Ins. Cary. N.C

Sivritepe N (1995). Asmalarda Tuza Dayanıklılık Testleri ve Tuza Dayanımda Etkili Bazı Faktörler Üzerinde Araştırmalar. Uludağ Üniversitesi, Fen Bilimleri Enstitüsü, Bahçe Bitkileri Anabilim Dalı, (Doktora tezi, basılmamış), Bursa, 176s.

Taleisnik E, Peyrano G, Arias C (1997). Respose of chloris gayana cultivars to salinity. 1. Germination and Early Vegetatif Growth. Trop. Grassl. 31: 232-240.

Turhan E (2002). Farklı Ortamlarda Yetiştirilen Çileklerin Tuza Dayanıklılık Fizyolojileri Üzerine Araştırmalar (Doktora tezi basılmamış). Uludağ Üniversitesi Fen Bilimleri Ens., Bursa.

Wahome PK, Jesch HH, Grittner I (2001a). Mechanisms of salt stress tolerance in two rose rootstocks: Rosa chinensis 'Major' and R. rubiginosa. Scientia Hort.,87: 207-216.

Wahome PK, Jesch HH, Pinker I (2001b). Effect of sodium chloride stress on rosa plants grown in vitro. Scientia Hort., 90: 187-191.

Wyn Jones RG, Lunt OR (1967). The function of calsium in plants. Bot. Rev., 33:407.

Yaşar F (2003). Tuz Stresi Altındaki Patlıcan Genotiplerinde Bazı Antioksidant Enzim Aktivitelerinin in vitro ve in vivo Olarak İncelenmesi. (Doktora tezi basılmamış). Yüzüncü Yıl Üniversitesi Fen Bil. Enst., Van.

Yaşar F, Özpay T, Üzal Ö, Ellialtığlu Ş (2006a). Karpuzun Tuz Stresine Olan Tepkisinin Belirlenmesi. 6. Sebze Tarımı Sempozyumu. 19-22 Eylül 2006. Kahramanmaraş. 250-252.

Yasar F, Uzal O, Tufenkci S., Yildiz K(2006b). Ion accumulation in different organs of green bean genotypes grown under salt stress. Plant Soil Environ., 52 (10): 476-480.

Yasar F (2007). Effects of salt stress on ion and lipidperoxidation content in green beans genotypes. Asian Journal of Chemistry, Vol. 19(3): 1165-1169.

Yaşar F, Ellialtıoğlu Ş, Özpay T, Üzal Ö (2007). Tuz Stresi Altındaki Karpuzların (Citrullus lanatus (Thunb.)Mansf.) Genotipik Farklılıklarının Belirlenmesi. Türkiye V. Ulusal Bahçe Bitkileri Kongresi, 4-7 Eylül 2007. Erzurum. 67-71.

Yıldız K, Üzal Ö, Yılmaz H (2008). Consequences of NaCl Salinity on Growth and Ion Accumulation in Selected Strawberry Cultivars, European Journal of Horticultural Science, 73(2):69-72.

Zekri M (1991). Effects of $\mathrm{NaCl}$ on growth and physiology of Sour Orange and Cleopatra Mandarin Seedlings. Scientia Hort., 305-315. 